\title{
A Correlation Study about Severity of COVID-19 Infection in association with Low Eosinophil Count
}

\author{
E. Prakash Murthy*, B. Hari Prasanth and R. Senthil Kumar \\ Microsmart Diagnostics Pvt Ltd, Mannargudi, Tamilndau, India \\ *Corresponding author
}

Keywords

RMB-ACE2

complex, Hibeco

virus, Lineage A

(Embeco virus),

Lineage C

(Merbeco virus),

Lineage D (Nobeco

virus)

Article Info

Accepted:

12 April 2021

Available Online:

10 May 2021
Covid19 is an infectious disease caused by SARS -COV2, the novel corona virus. This correlation study is done in patients who had complaints of fever, myaligia, cough and dyspnea within 1 week duration, by taking their Complete blood count using a Hematological Auto analyser. Their Eosinophil levels are noted and those with low eosinophil count of less than $1 \%$ are subjected to RTPCR test for SARS COV2 using Nasopharyngeal and Oropharyngeal swab and CT CHEST is done. Positive predictive value of $78 \%$ was observed for RTPCR in those with low Eosinophil count. CT CHEST showed CORADS of greater than 4 in all of them with low Eosinophil count and a opacity score of $>16 / 25$ was observed in those with extremely low eosinophil count of 0.0 to $0.3 \%$ and a opacity score of $8 / 25$ to $15 / 25$ was observed in those with eosinophil count of 0.4 to $0.7 \%$ and a CT score of $<8 / 25$ was found in those with eosinophil count of 0.8 to $0.9 \%$. This study highlights the significance of $\mathrm{CBC}$ test which is easily accessible, fast and very much economical, can be used as a primitive tool to find covid19 infection in remote areas which don't have immediate access to RTPCR and CT CHEST and also a reliable tool to predict the prognosis of the disease.

\section{Introduction}

Covid 19 is an infectious disease caused by Novel corona virus. It belongs to the lineage B (Sabecovirus) of the corona virus family. The other lineages are Lineage A (Embeco virus), Lineage C (Merbeco virus), Lineage D (Nobeco virus) and Hibeco virus. SARS COV2 is an enveloped virus with positivesense single stranded RNA. It is believed to be transmitted from Pangolins to human beings during its official first outbreak in the city of Wuhan, at the Hubei province of Mainland China during December 2019.

The envelope of the virus holds a Spike glycoprotein which has a Receptor Binding Motif (RMB). Upon activation by the Transmembrane serine protease 2 (TMPRSS2), it binds with the ACE2 receptors 
present in the human cells more abundantly in the nasopharyngeal and oropharygeal mucosa. Following attachment, RMB-ACE2 complex is formed and the viral RNA enters the host cytoplasm.

With the help of RdRp enzyme (RNA Dependant RNA Polymerase), the host cells are forced to manufacture new viral RNA copies and eventually the assembly and release of Fully equipped viral load occurs.

Covid19 comprises of a wide range of symptoms in human beings with its incubation period varying from 1-14 days. Fever, Myalgia, extreme fatigue, anosmia, agusia, dry cough and dyspnea are the most common among the symptoms.

The main aim of this study to perform Complete blood count (Hemogram) in patients with symptoms of covid19 and those with low eosinophil count (less than 1.0) are further evaluated by conducting RT-PCR test using their nasopharyngeal and oropharygeal swabs and CT-Chest to find CORADS score and thereby correlating the severity of covid 19 with low Eosinophil count.

\section{Materials and Methods}

\section{Sample size}

347 patients

\section{Specimen}

Whole blood for Complete Blood Count done using Mindray BC5310 Hematology analyser, Nasopharyngeal and Oropharygeal swab for RT PCR using ALTA REALSTAR and Computerised Tomography of CHEST.

\section{Place of study}

Microsmart Diagnostics Pvt Ltd, Mannargudi and KG Multi-speciality Hospital, Molecular Diagnostics and Research centre, Thanjavur

\section{Period of study}

June to November 2020

\section{Inclusion criteria}

Age above 18, with or without co-morbities

Symptoms of Fever, Myalgia, cough, fatigue, anosmia and aguesia

Eosinophil Count $<1.0 \%$

Period of illness : 1 to 14 days

\section{Results and Discussion}

Out of the 347 patients with Eosinophil count less than $0.9 \%, 270$ patients tested positive (78\%) for SARS COV2 RT-PCR by molecular diagnosis. Positivity rate decreased as the day of testing after onset of illness increased. Eosinophil percentage gradually decreases as the infection progresses. Low levels of eosinophil count is associated with Higher NLR (Neutrophil Lymphocyte Ratio) and Severe Pneumonia as evident by the CT CHEST CORADS Score. NLR $>3.0$ is a predictor for poor prognosis

SARS COV2 infection triggers cytokine storm which causes a rapid rise of interleukins such as IL6, IL3, IL5 and many other pro inflammatory cytokines. Rise in the levels of IL6 targets lymphocytes and causes Lymphopenia, whereas increase in the levels of IL3 and IL5, whose target zones are mast cells and eosinophils respectively, eventually produces fall in eosinophil count. 
Table.1 No. of cases with percentage of eosinophils corresponding to the day of onset of illness

\begin{tabular}{|c|c|c|c|c|}
\hline $\begin{array}{c}\text { Onset of } \\
\text { illness }\end{array}$ & $\begin{array}{c}\text { Eosinophils } \\
\mathbf{0 . 0} \text { to } \mathbf{0 . 3 \%}\end{array}$ & $\begin{array}{c}\text { Eosinophils } \\
\mathbf{0 . 4} \text { to 0.7\% }\end{array}$ & $\begin{array}{c}\text { Eosinophils } \\
\mathbf{0 . 8} \text { to 0.9\% }\end{array}$ & $\begin{array}{c}\text { RT PCR } \\
\text { Positive }\end{array}$ \\
\hline 0 to 5 days & 5 & 34 & 106 & 158 \\
\hline 6 to 10 days & 16 & 58 & 64 & 90 \\
\hline 11 to 14 days & 28 & 10 & 36 & 22 \\
\hline Total cases & 49 & 102 & 206 & 270 \\
\hline
\end{tabular}

Table.2 Eosinophil \% and corresponding CT CHEST CORADS Severity score

\begin{tabular}{|c|c|c|c|}
\hline Eosinophil \% & $\begin{array}{c}\text { CT CHEST } \\
\text { CORADS } \\
\text { SEVERITY SCORE }\end{array}$ & No.of Patients & $\begin{array}{c}\text { NEUTROPHIL } \\
\text { LYMPHOCYTE } \\
\text { RATIO( NLR) }\end{array}$ \\
\hline 0 to $0.3 \%$ & $>16 / 25$ & 49 & $>5.0$ \\
\hline 0.4 to $0.7 \%$ & $8 / 25$ to $15 / 25$ & 102 & 3 to 5.0 \\
\hline 0.8 to 0.9 & $<8 / 25$ & 206 & $<3.0$ \\
\hline
\end{tabular}

Pie chart.1 RT PCR Positive \% with relation to the day of collection of swab after the onset of illness

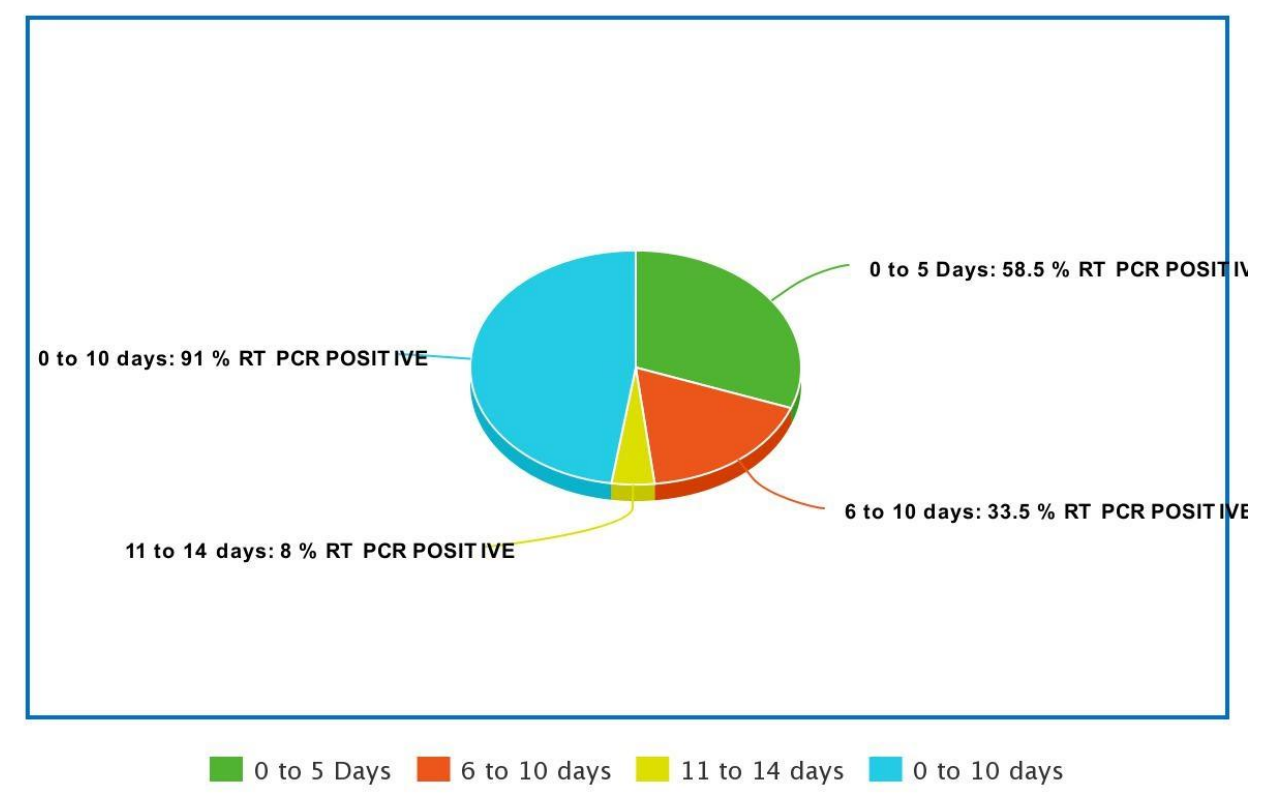


Picture.1 Standard curve ellicited by Alta Realstar RT PCR for SARS COV2 RdRp gene

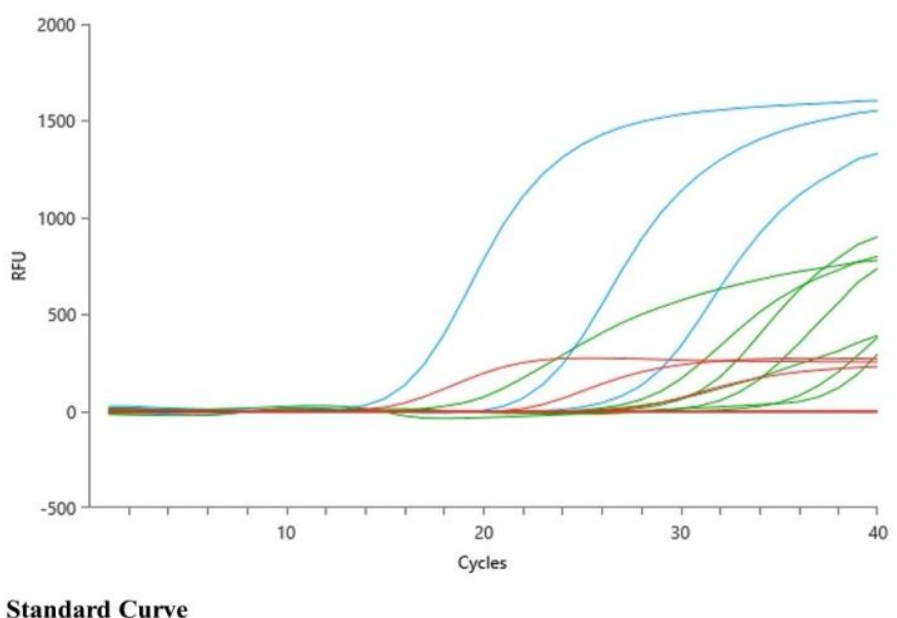

Standard Curve

Picture.2 Ground Glass Opacity in bilateral lung lobes captured in High Resolution CT CHEST depicting CORADS Severity Score

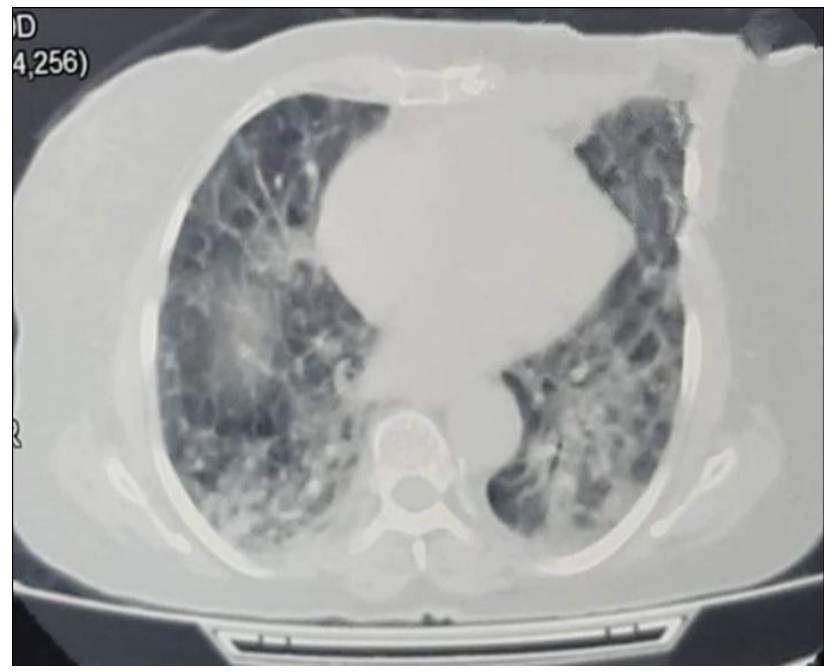

Low levels of eosinophils triggers sudden production of Bradykinin which is termed as " Bradykinin Breeze" which causes increased vaso dilatation of the pulmonary vasculature thereby makes way for secretion of fluid and increase in hyaluronic acid which creates a "hydrogel" like atmosphere near the alveoli and preventing oxygen uptake.

This peculiar characteristic feature of vasodilation without brocho-constriction is the main reason for "happy hypoxia " in Covid 19 pneumonia. This study clearly correlates the severity of covid19 patients with low Eosinophil count. As the infection progresses, eosinophil count decreases along with lymphocyte count. Lower the eosinophil count, higher the Neutrophil Lymphocyte Ratio, higher the CORADS Score, worser the prognosis. Hence, CBC test can be used as a cost effective tool to predict the prognosis of covid19 patients. It is easily available, affordable and the results can be obtained within 15 minutes. 


\section{References}

https://www.ncbi.nlm.nih.gov/pmc/articles/P MC7410499/ https://www.thelancet.com/journals/lanres/arti cle/PIIS2213-2600(20)30404-5/fulltext https://www.sciencedirect.com/science/article/ pii/S1201971220303015

\section{How to cite this article:}

Prakash Murthy, E., B. Hari Prasanth and Senthil Kumar, R. 2021. A Correlation Study about Severity of COVID-19 Infection in association with Low Eosinophil Count. Int.J.Curr.Microbiol.App.Sci. 10(05): 10-14. doi: https://doi.org/10.20546/ijcmas.2021.1005.002 